\title{
Understanding Powder X-ray Diffraction Profiles from Layered Minerals: The Case of Kaolinite Nanocrystals
}

\author{
Alberto Leonardi ${ }^{*}+, 1$ \& David L. Bish ${ }^{2}$ \\ 1. Department of Earth and Atmospheric Sciences, Indiana University, Bloomington, Indiana 47405, U.S.A. \\ 2. Department of Chemistry, Indiana University, Bloomington, Indiana, 47405, U.S.A.
}

Layered Minerals, Clays, Kaolinite, Nanocrystal, Layer Stacking, Powder X-ray Diffraction.

\section{SUPPORTING INFORMATION}

State of The Art of Line Profile Analysis (LPA) of Powder Xray Diffraction Data. LPA methods such as Rietveld refinement ${ }^{1,2}$ and whole powder pattern modelling (WPPM) 3,4 can account with physical significance only for small deviations of the crystal structure from a well-defined lattice.5,6 Layer stacking disorder cannot be described with a given structure as it evolves toward the limit of a turbostratic microstructure, in which the in-plane structure of the layers is randomly oriented. Other methods have been suggested to describe the nature of stacking defects. For example, the expert method introduced by Plançon in 1990 provides estimates of several structural characteristics, such as the probability of

\begin{tabular}{|c|c|c|c|}
\hline Atom & $\mathrm{X}$ & Y & $\mathrm{Z}$ \\
\hline Si (1) & 0.9942 & 0.3393 & 0.0909 \\
\hline Si (2) & 0.5064 & 0.1665 & 0.9130 \\
\hline Al (1) & 0.2971 & 0.4957 & 0.4721 \\
\hline $\mathrm{Al}(2)$ & 0.7926 & 0.3300 & 0.4699 \\
\hline $\mathbf{O}(\mathbf{1})$ & 0.0501 & 0.3539 & 0.3170 \\
\hline $\mathrm{O}(\mathbf{2})$ & 0.1214 & 0.6604 & 0.3175 \\
\hline $\mathrm{O}(3)$ & 0.0000 & 0.5000 & 0.0000 \\
\hline $\mathrm{O}(4)$ & 0.2085 & 0.2305 & 0.0247 \\
\hline$O(5)$ & 0.2012 & 0.7657 & 0.0032 \\
\hline $\mathrm{OH}(\mathbf{1})$ & 0.0510 & 0.9698 & 0.3220 \\
\hline $\mathrm{OH}(2)$ & 0.9649 & 0.1665 & 0.6051 \\
\hline $\mathrm{OH}(3)$ & 0.0348 & 0.4769 & 0.6080 \\
\hline $\mathrm{OH}(4)$ & 0.0334 & 0.8570 & 0.6094 \\
\hline \multicolumn{4}{|c|}{ Space Group C1 } \\
\hline$a=5.1554 \AA$ & \multirow{2}{*}{\multicolumn{2}{|c|}{$\begin{array}{l}b=8.9448 \AA \\
\beta=104.862^{\circ}\end{array}$}} & $c=7.4048 \AA$ \\
\hline$\alpha=91.7000^{\circ}$ & & & $\gamma=89.8220^{\circ}$ \\
\hline
\end{tabular}

Table S1. Kaolinite crystal structure. Unit-cell parameters and relative atom positions refined by Bish \& Von Dreele in 1989 for Keokuk kaolinite. ${ }^{20}$

\begin{tabular}{ccccc} 
Atom & X & Y & Z & Octahedral Site \\
\hline Al (1) & $\mathbf{0 . 2 9 7 1}$ & $\mathbf{0 . 4 9 5 7}$ & $\mathbf{0 . 4 7 2 1}$ & A \\
Al (2) & $\mathbf{0 . 7 9 2 6}$ & $\mathbf{0 . 3 3 0 0}$ & $\mathbf{0 . 4 6 9 9}$ & B \\
Al (3) & $\mathbf{0 . 2 9 4 9}$ & $\mathbf{0 . 1 6 2 9}$ & $\mathbf{0 . 4 7 1 0}$ & C
\end{tabular}

Table S2. Octahedral sites. The $\mathrm{C}$ octahedral site was derived from the average coordinates of the known $\mathrm{Al}$ sites. stacking-fault defects based on the relative position and intensity of a few characteristic peak profiles over a narrow range of scattering angles (i.e., $\mathrm{CuK} \alpha 2 \theta$ range from $18^{\circ}$ to $\left.40^{\circ}\right) .7$ Evolving from the approach first introduced in $2004,{ }^{8}$ Ufer proposed a Rietveld-like approach that uses two distinct crystal structures to independently describe the ool and $h k l$ reflections.9,10 The ool reflections are influenced only by the persistence of the layer stacking, ${ }^{11}$ whereas the $h k l$ reflections are affected by the degree of stacking disorder. However, the reliability of the properties estimated by these methods is limited by the effective interpretation of the limited set of diffraction features used in analysis. The more sophisticated BGMN 9,10,12,13, DIFFaX+ 14,15, and CIREALS 16 software approaches model the diffraction profile by a combination of the accurate structure factor of each component in the powder sample. Recursive algorithms attempt then to match experimental data, thereby resolving the characteristic stacking disorder. Some contributions, such as size distribution and shape of the clay nanocrystals or free roto-translation of the layers in the stack, are nonetheless still ignored to facilitate refinement efficiency. The combination of the theoretical algorithm proposed by Drits and Tchoubar in 1990 and a least-squares software application developed by Sakharov and Naumov ${ }^{17,18}$ partially addressed such limitations. As an example, although considering crystallite-size distributions, the mean and variance were assumed dependent on each other, ${ }^{19}$ limiting the flexibility and reliability of the methodology.

Microstructural characteristics of the kaolinite models. The kaolinite structure of Table $\mathbf{S} \mathbf{1}$ was periodically repeated in space to form an infinite single crystal. The ideal sequence of distinct layers was identified. Stacking disorder was than incorporated into the structure by perturbing the configuration of the layers. Stacking-fault defects were otherwise obtained by layer-layer change of the crystal structure, which we refer to as the layers' configuration states. Nanocrystal models were finally obtained selecting those atoms with an imprint within a circular perimeter in-plane with the layers (Figure S1).

Four types of layer-layer stacking disorders were incorporated by change of:

i. Stacking distance (i.e., repeat). The layers were displaced along the stacking direction normal to the layer plane, not the c lattice vector. 
ii. Lateral indentation. The circular perimeter used to select atoms from the infinite crystal was shifted layer by layer along random orientations over $360^{\circ}$. A constant shift magnitude was used.

iii. Structure misorientation. The layers were rotated with rotation axis parallel to the layer stacking direction. The rotation center was placed at the origin of the layer lattice structure. The rotation angle was either defined relative to the nearest neighbor or to the first layer in the stack (i.e., relative to the preceding layer in the stacking sequence or the unperturbed configuration).

iv. Structure shift. The layers were shifted normal to the layer stacking direction (i.e., in-plane with the layer) along random orientations over $360^{\circ}$. A constant shift magnitude was used.

These layer-layer configuration perturbations were either propagated or not in the stacking sequence.

In addition to the unperturbed layer's configuration state, C, alternative states were obtained according to the models available from the literature (see Figure $\mathbf{S 6 A}, \mathbf{S}_{\mathbf{7}} \mathbf{A}, \mathbf{S 8 A}$ or 4A):

Brindley and Robinson (1946). ${ }^{21}$ Two additional states were obtained by shift of either $+\mathbf{b} / 3$ (state $\mathbf{A}$ ) or $-\mathbf{b} / 3$ (state B)

Murray (1954).22 Two additional states were obtained by rotation of the unit structure by $\pm 120^{\circ}$. We slightly adjusted the angles to $+120.09^{\circ}$ and $-119.82^{\circ}$ to account for the direction of the mirror plane $n$ through the octahedral vacancies in the triclinic cell, which has an angle with the a-vector of $\sim 59.91^{\circ}$ instead of the ideal $60^{\circ}$.

Newnham and Giese (1961, 1982).23,24 Although the same configuration states of the Brindley and Robinson model were used, the change of state is limited to $+\mathbf{b} / 3$. Therefore, $\mathbf{A} \rightarrow \mathbf{B}, \mathbf{B} \rightarrow \mathbf{C}$, and $\mathbf{C} \rightarrow \mathbf{A}$ are the only allowed stacking-fault sequences of the states as named for the Brindley and Robinson model.

Plançon and Tchoubar (1977). ${ }^{25}$ Vacant and occupied octahedral sites were swapped (i.e., an $\mathrm{Al}$ atom was moved to the vacant octahedral site leaving empty (vacant) the previously occupied site). The two Al sites of the kaolinite structure were chosen from the three sites of Table S2. The third site left vacant is used to identify the two additional states: A and $\mathbf{B}$.

Bookin (1989). ${ }^{26}$ One additional state was obtained via enantiomorphism with the mirror plane $n$.

The configuration states were assumed to change with a constant probability of transition (i.e., stacking-fault probability) from one state to another, and no preferential transition type or long-range correlations were considered.

Figure S2. Destructive cross contribution from turbostratic stacking configuration. Although the ool-basal peaks becomes sharper with an increasing number of layers, the background destructive contribution remains unchanged. In addition to magnifying both the ool-basal reflections and the background profile, neglecting the layer thickness collapses the background to an exponential profile. Profiles from nanocrystals with different layer diameter fully overlap.
A
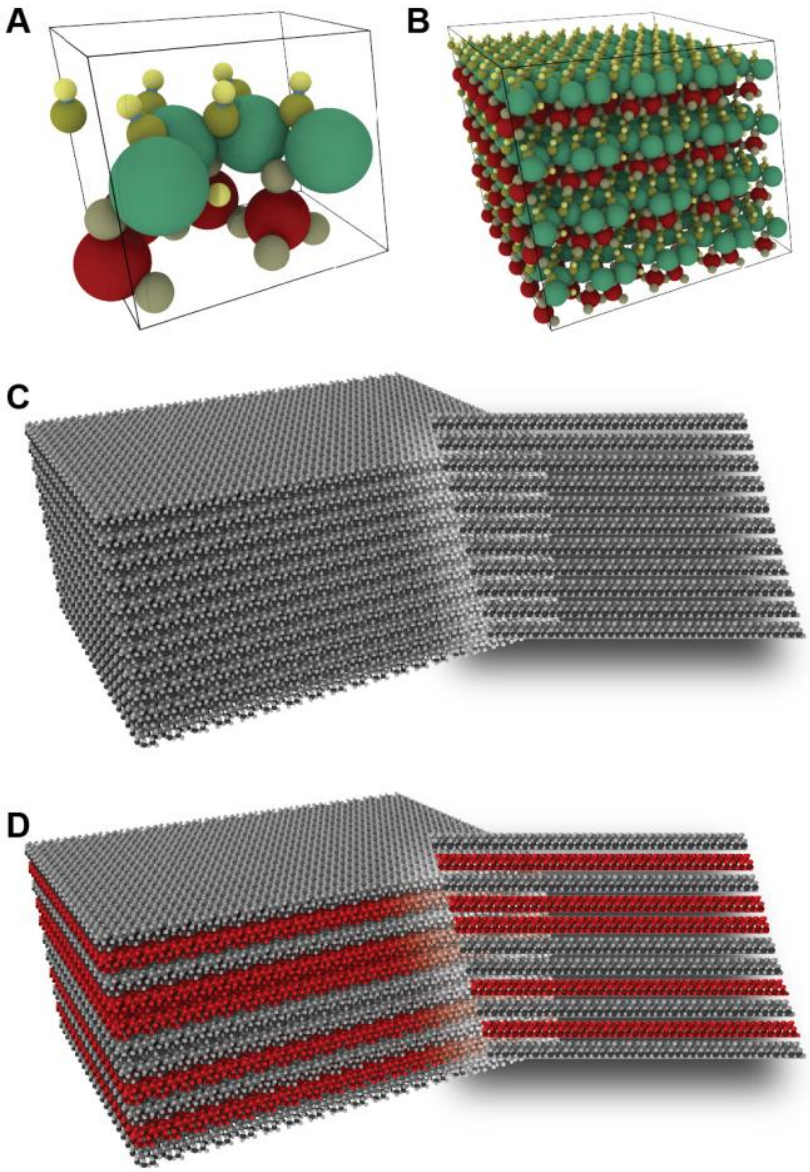

E
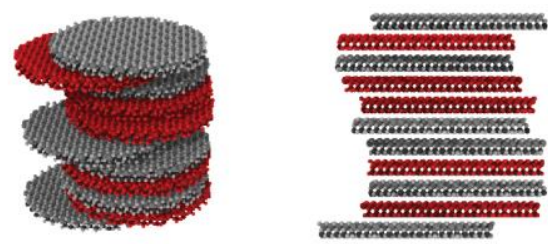

Figure S1. Modelling of kaolinite nanocrystals. From A to $\mathbf{B}$, the kaolinite unit structure was repeated in space. From $\mathbf{C}$ to $\mathbf{D}$, stacking disorder was incorporated in the infinite perfect crystal. D, the red layers highlight a possible set of perturbed layers. From D to E, finite-size nanocrystals were finally extracted.

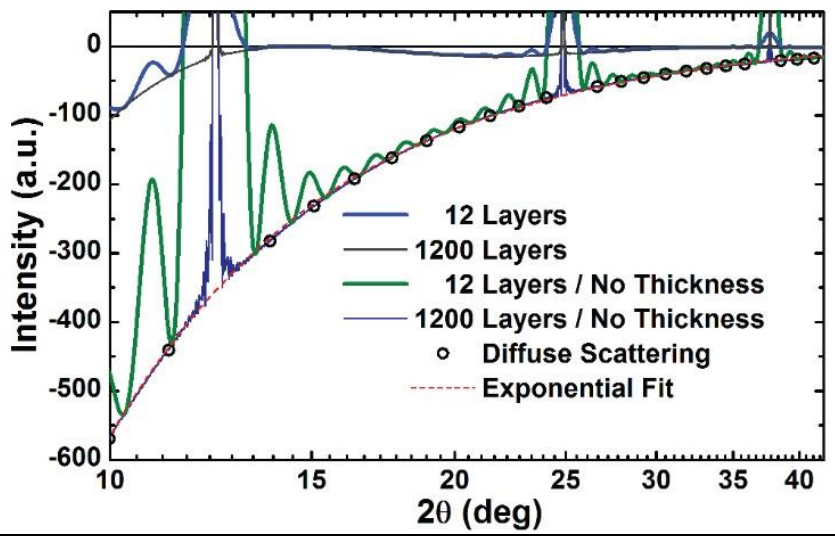




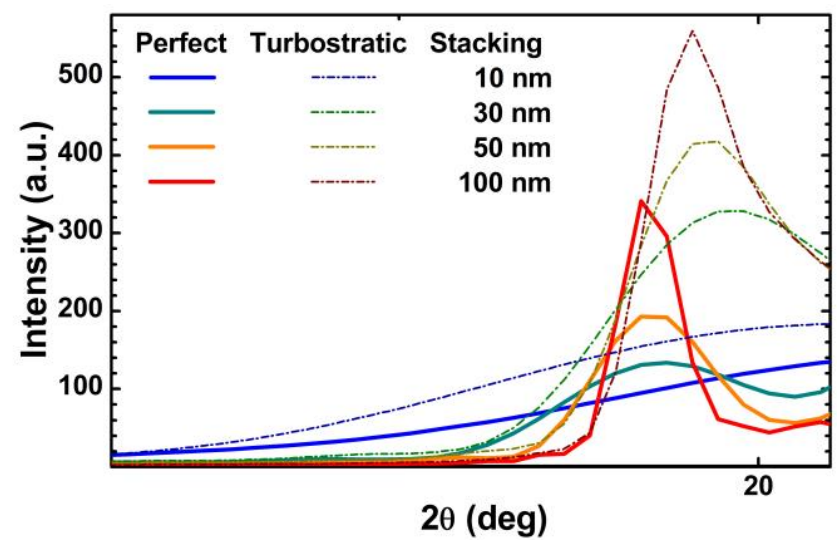

Figure $S_{3}$. Variation of the $h k l$ low-angle tail with layer diameter. The low-angle tails of $h k l$ peaks or corresponding reflection bands show an inverse correlation between apparent diffraction angle of the centroid and breadth of the peaks.

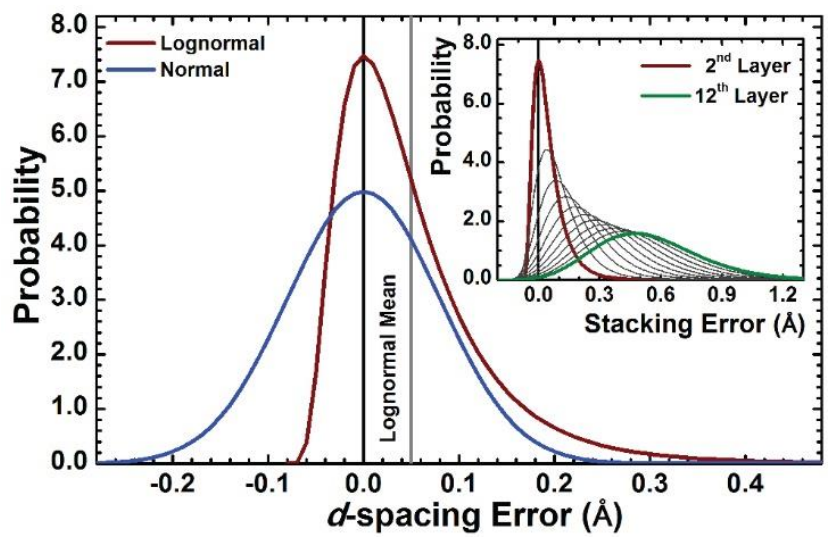

Figure S4. Probability distributions of nearest-neighbor layer $\boldsymbol{d}$-spacing error. The standard deviation of both Gaussian and log-normal (mode equal o.o8o $\AA$ ) probability distributions was chosen as 0.080 $\AA$. The Lognormal function was shifted to ensure the perfect stacking configuration is the most frequent. As the nearest-neighbor layer $d$-spacing error sums over subsequent interlayers, the stacking error between the bottom and the $n^{\text {-th }}$ layers is the convolution of the probability function with itself $n$ times. Whereas the convolution of two Gaussians is a Gaussian whose variance is the sum of the variances, the inset shows the resulting probability distributions for the Lognormal function.

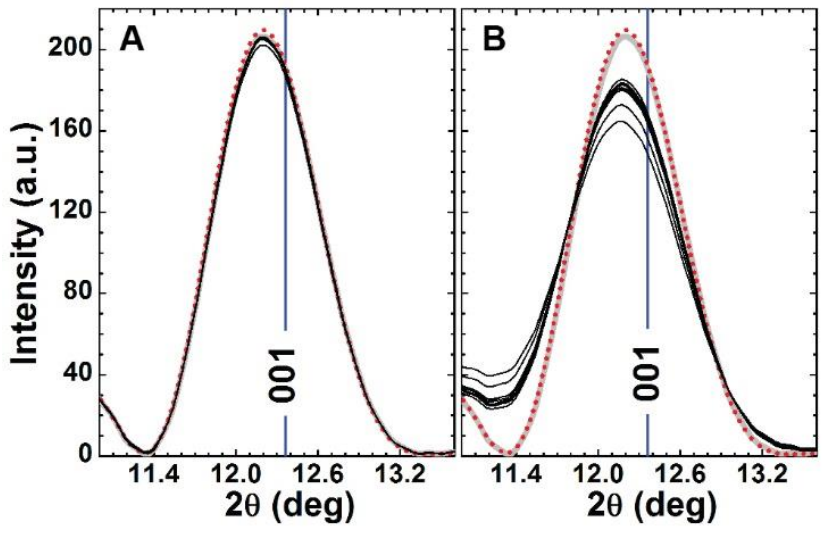

Figure $\mathrm{S}_{5}$. oor reflection for various dispersions of layer structure misorientation. A, misorientation angle relative to the perfect stacking configuration. $\mathbf{B}$, misorientation angle relative to the nearest-neighbor layer. The PXRD profile for the perfect (gray line) and turbostratic (red dot) microstructures are shown as guides for the eye.

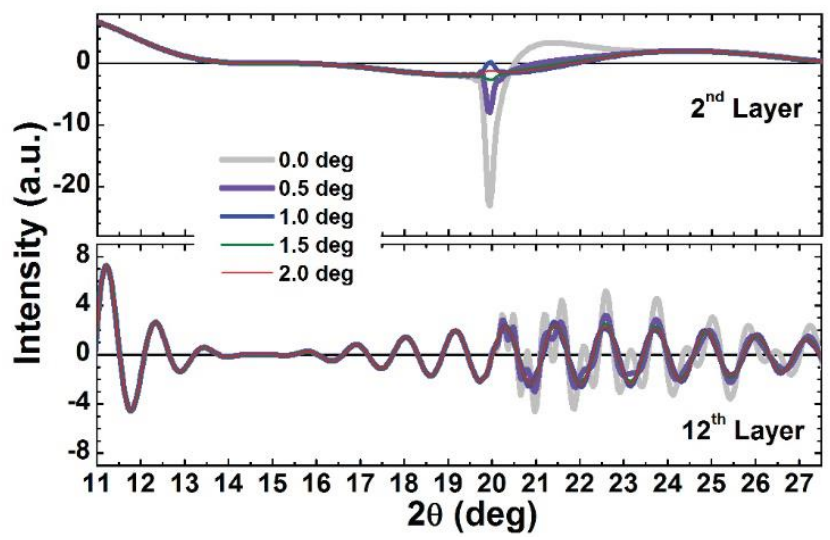

Figure S6. Intensity cross contribution from a pair of misoriented layers. Interference diffraction between the bottom (i.e., ${ }^{-}{ }^{\text {st }}$ ) and the $n^{- \text {th }}$ layer as a function of the structure misorientation angle. 
Figure S7, S8 and S9. A, crystallographic relation between the reference structure (black), the enantiomorphic (red), and the $\pm 120^{\circ}$ rotation (green and blue) models. In addition to the unit-cell base (rectangle-like), the c-vector (continuous line), and the octahedral sites (circle), the mirror plane $n$ (dash-dot line) is also shown. The crystal structure was shifted in the $a b$ plane such that the $C$ octahedral vacancy is on the c-vector (open circle). Note that the $C$ octahedral vacancy is not at the origin of the Cartesian plane because of the inclination of the c-vector. B-F, Virtual PXRD profiles from defected kaolinite nanocrystals with 12 layers of $50 \mathrm{~nm}$ diameter. The PXRD profiles for the perfect (gray line) and turbostratic (red dot) microstructures are shown as guides for the eye. Different stacking-fault models considered were: octahedral sites swap (B), structure shift of $\pm \mathbf{b} / 3$ or only $+\mathbf{b} / 3$ (C and D, respectively), structure rotation of about $\pm 120^{\circ}(\mathrm{E})$, enantiomorphism (F). Note that the rotations of $\pm 120^{\circ}$ were adjusted (by less than $0.1^{\circ}$ ) to consider a triclinic unit cell, which has an angle between the a-vector and the $n$ plane slightly out of $60^{\circ}$.
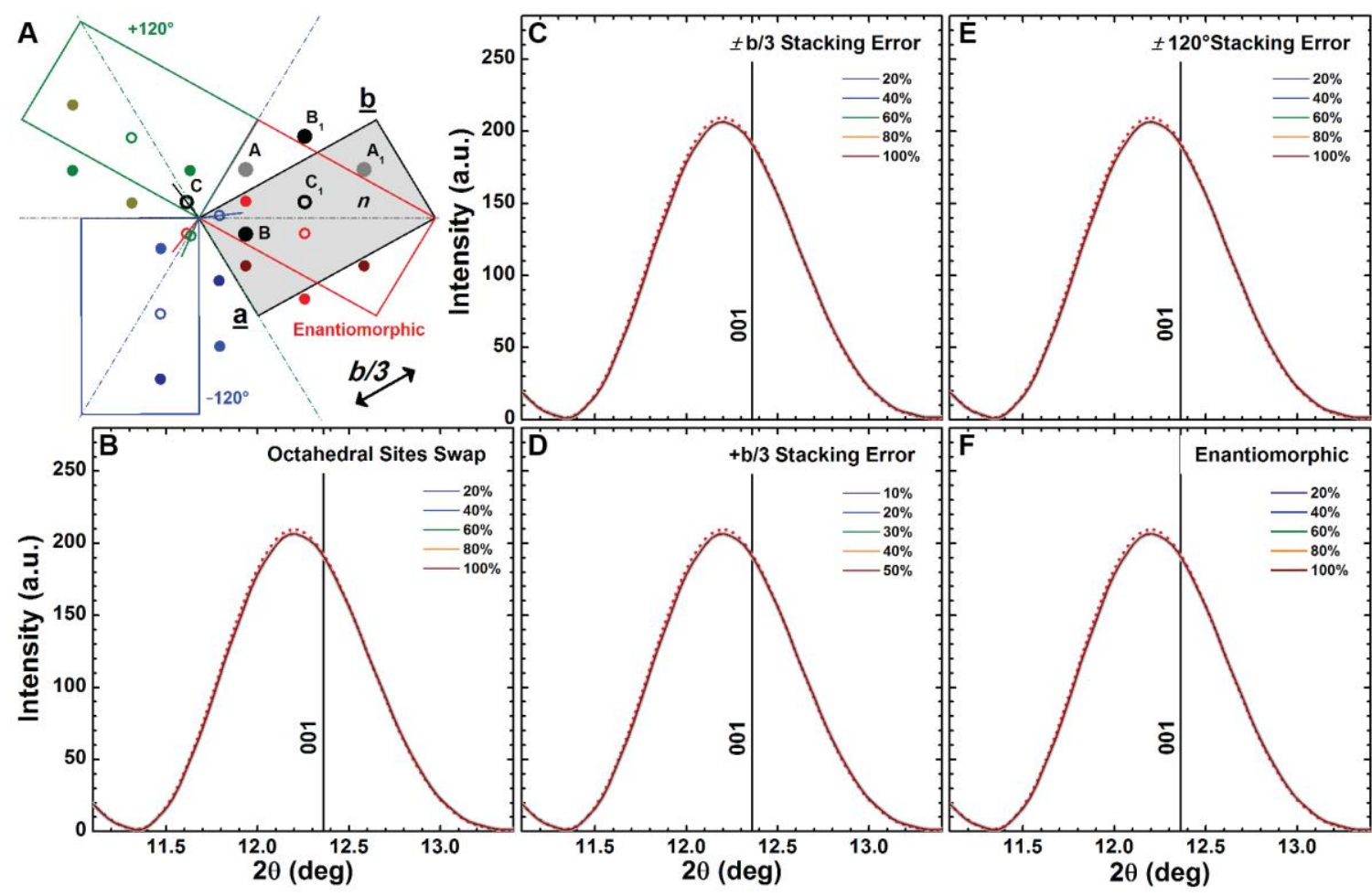

Figure $S_{7}$. Broadening of the oor reflection from stacking-fault defects. See above for details. 


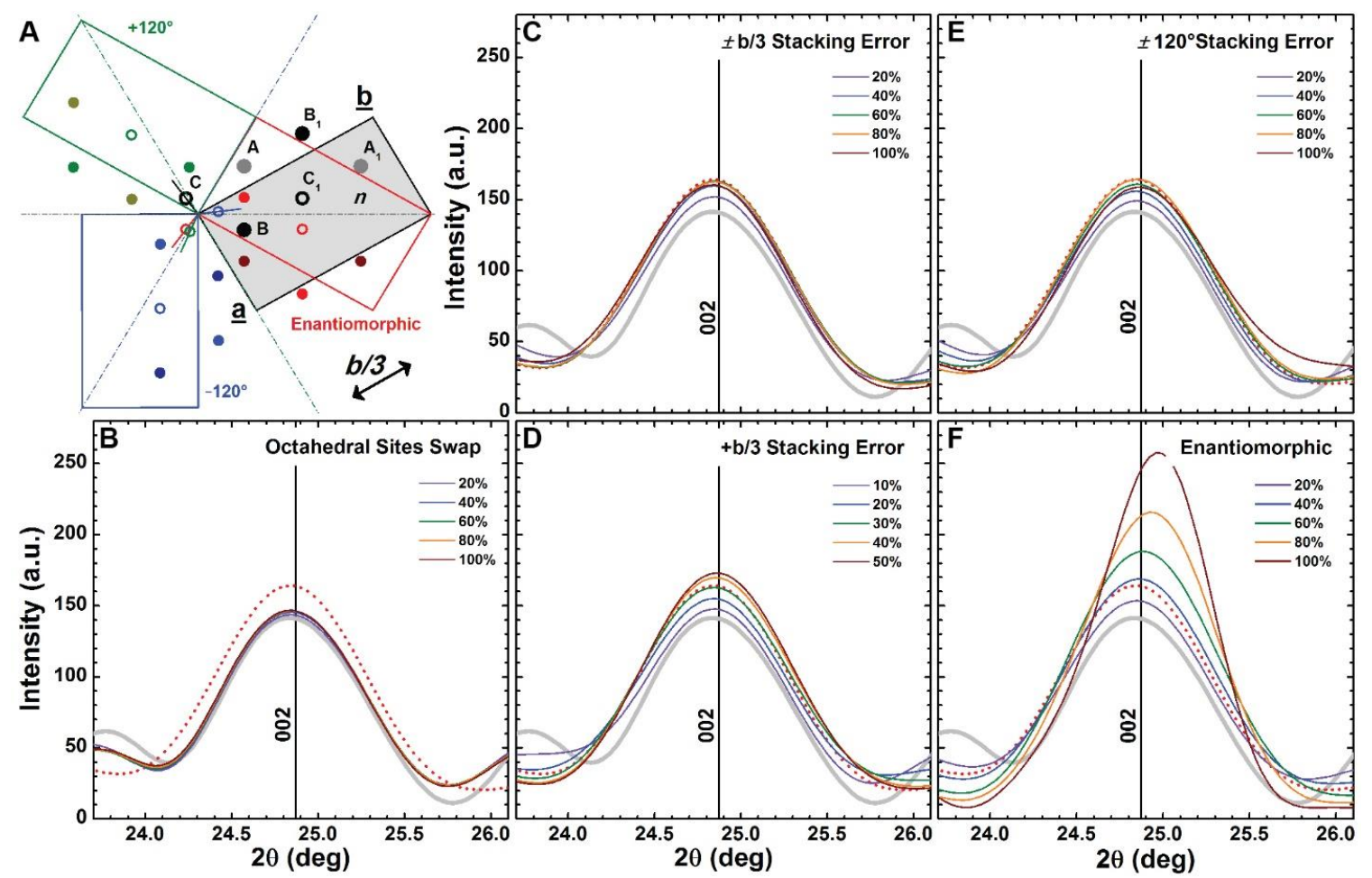

Figure S8. Broadening of the ooz reflection from stacking-fault defects. See above for details.
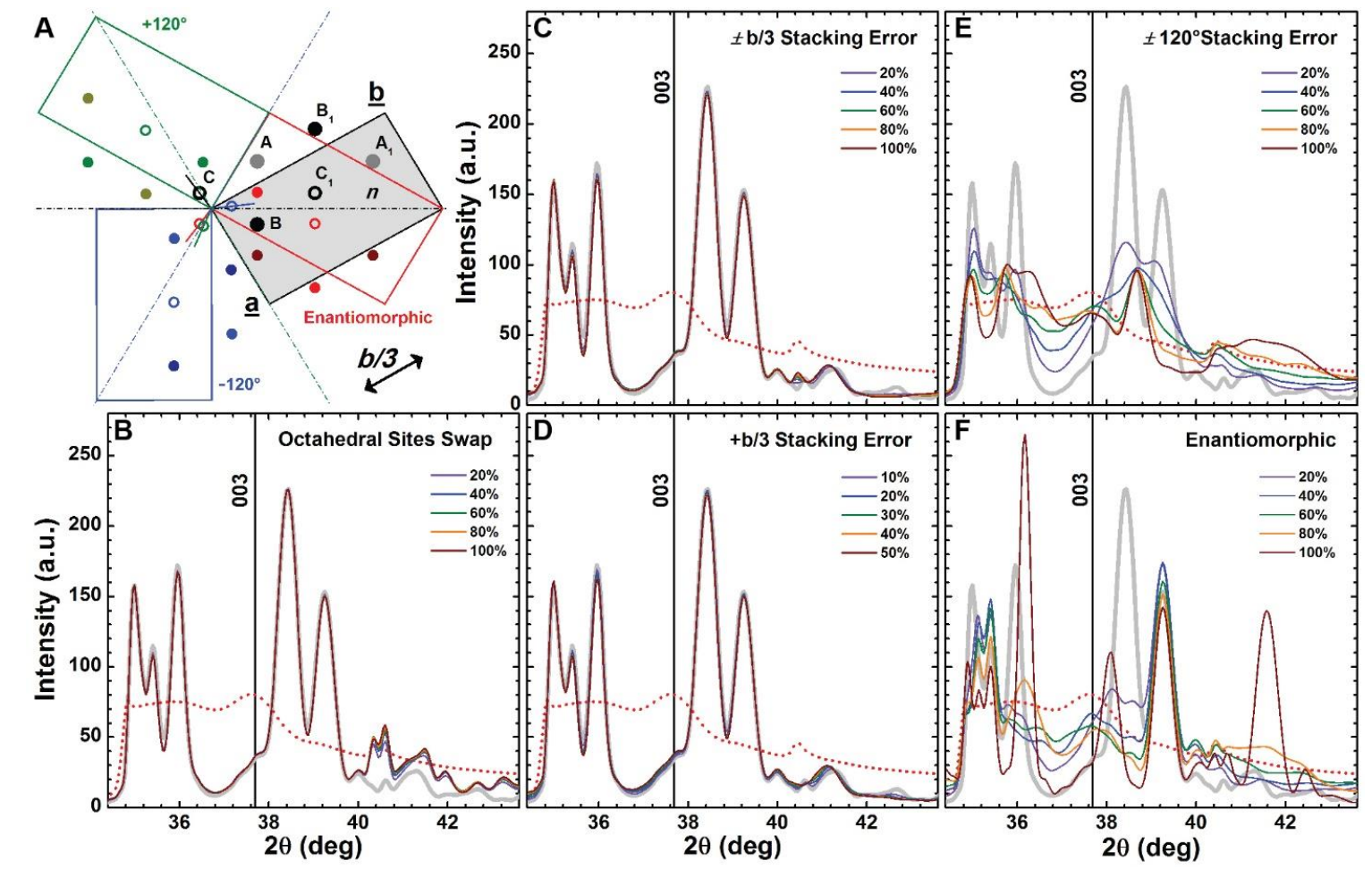

Figure S9. Broadening of the ooz reflection and nearby $h k l$ band from stacking-fault defects. See above for details. 


\begin{tabular}{|c|c|c|}
\hline $2 \theta(\mathrm{deg})$ & $\begin{array}{l}\text { API-9 Reference } \\
\text { Intensity (a.u.) }\end{array}$ & $\begin{array}{c}\text { Relative Intensity } \\
\text { Variation (\%) }\end{array}$ \\
\hline 12.2 & 10261800000 & $\mathbf{o}$ \\
\hline 19.8 & 2285100000 & -78 \\
\hline 20.1 & $255^{225000}$ & -98 \\
\hline 20.3 & 6000960000 & -42 \\
\hline 20.8 & 159315000 & -98 \\
\hline 21.3 & 5580500000 & -46 \\
\hline 22.6 & 51934700 & -99 \\
\hline 23.1 & 3760380000 & -63 \\
\hline $23 \cdot 7$ & 1655540000 & -84 \\
\hline 24.8 & 7573070000 & -26 \\
\hline 25.8 & 54434300 & -99 \\
\hline 26.4 & 2138310000 & -79 \\
\hline 27.1 & 16034300 & -100 \\
\hline 28.6 & 558133000 & -95 \\
\hline 36.0 & 2165830000 & -79 \\
\hline 38.4 & 3281460000 & -68 \\
\hline $39 \cdot 3$ & 3593180000 & -65 \\
\hline $49 \cdot 5$ & 797096000 & -92 \\
\hline 50.6 & 36220600 & -100 \\
\hline $53 \cdot 7$ & 518239000 & -95 \\
\hline $57 \cdot 9$ & 210614000 & -98 \\
\hline 63.2 & 412614000 & -96 \\
\hline 69.2 & 261352000 & -97 \\
\hline 72.2 & 1245060000 & -88 \\
\hline 73.2 & 570192000 & -94 \\
\hline 76.2 & 789607000 & -92 \\
\hline 77.0 & 905561000 & -91 \\
\hline $77 \cdot 5$ & 465563000 & -95 \\
\hline 78.8 & 263054000 & -97 \\
\hline \multicolumn{3}{|c|}{$\begin{array}{l}\text { able S3. Characteristic diffraction reflections. CuKa } 2 \theta \\
\text { ositions of the characteristic diffraction reflections used to } \\
\text { stimate the crystallinity index and degree of stacking errors } \\
\text { irst column). The intensity from a sample of perfect crystals } \\
\text { ith size parameters estimated for the API-9 kaolinite stand- } \\
\text { d (second column). The intensity variation from a tur- } \\
\text { ostratic microstructure relative to a perfect microstructure } \\
\text { also provided (third column). }\end{array}$} \\
\hline
\end{tabular}
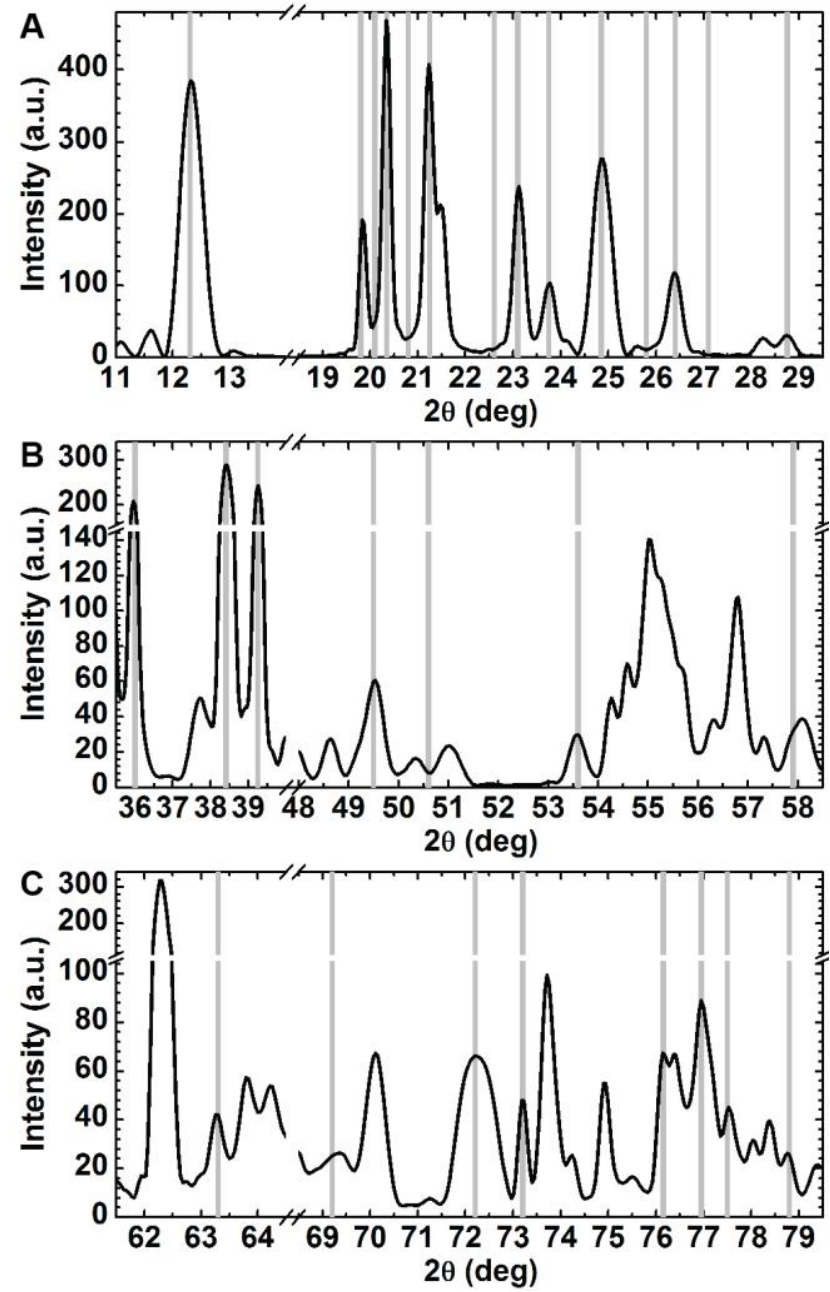

Figure S1o. Characteristic diffraction reflections. Positions of the characteristic diffraction reflections used to estimate the crystallinity index and degree of stacking errors (gray lines). 


\begin{tabular}{c|ccc|}
$\begin{array}{c}\text { Indentation } \\
(\%)\end{array}$ & $\begin{array}{c}\text { Misorientation } \\
(\mathbf{d e g})\end{array}$ & $\begin{array}{c}\text { Structure } \\
\text { Shift }(\AA)\end{array}$ & $\begin{array}{c}\text { Stacking } \\
\text { Fault }(\%)\end{array}$ \\
\hline 5.00 & 0.00 & 0.00 & o.oo \\
10.00 & 0.05 & 0.00 & 0.00 \\
15.00 & 0.10 & 0.00 & 0.00 \\
20.00 & 0.20 & 0.00 & 0.00 \\
25.00 & 0.30 & 0.00 & 1.00 \\
30.00 & 0.35 & 0.00 & 0.00 \\
35.00 & 0.40 & 0.05 & 3.00 \\
40.00 & 0.55 & 0.00 & 0.00 \\
45.00 & 0.65 & 0.00 & 0.00 \\
50.00 & 0.80 & 0.00 & 0.00 \\
& & &
\end{tabular}

\begin{tabular}{cccc}
$\begin{array}{c}\text { Indentation } \\
(\%)\end{array}$ & $\begin{array}{c}\text { Misorientation } \\
(\mathrm{deg})\end{array}$ & $\begin{array}{c}\text { Structure } \\
\text { Shift }(\AA)\end{array}$ & $\begin{array}{c}\text { Stacking } \\
\text { Fault }(\%)\end{array}$ \\
\hline 3.00 & 0.00 & 0.00 & 0.00 \\
14.00 & 0.00 & 0.00 & 0.00 \\
25.00 & 0.00 & 0.00 & 0.00 \\
36.00 & 0.00 & 0.00 & 0.00 \\
45.00 & & 0.00 & 0.00
\end{tabular}

\begin{tabular}{cccc}
$\begin{array}{c}\text { Indentation } \\
(\%)\end{array}$ & $\begin{array}{c}\text { Misorientation } \\
(\text { deg })\end{array}$ & $\begin{array}{c}\text { Structure } \\
\text { Shift }(\AA)\end{array}$ & $\begin{array}{c}\text { Stacking } \\
\text { Fault }(\%)\end{array}$ \\
\hline o.oo & 0.50 & 0.70 & 3.00 \\
o.oo & 1.00 & 1.10 & 0.00 \\
0.00 & 5.00 & 3.30 & 13.00 \\
o.oo & 10.00 & 3.40 & 21.00 \\
o.oo & 15.00 & 3.45 & 30.00
\end{tabular}

\begin{tabular}{cccc}
$\begin{array}{c}\text { Indentation } \\
(\%)\end{array}$ & $\begin{array}{c}\text { Misorientation } \\
(\mathrm{deg})\end{array}$ & $\begin{array}{c}\text { Structure } \\
\text { Shift }(\AA)\end{array}$ & $\begin{array}{c}\text { Stacking } \\
\text { Fault }(\%)\end{array}$ \\
\hline o.00 & o.10 & 0.60 & 2.00 \\
0.00 & 8.20 & 0.30 & 4.00 \\
0.00 & 34.00 & 0.10 & 0.00
\end{tabular}

\begin{tabular}{|c|c|c|c|}
\hline $\begin{array}{c}\text { Indentation } \\
(\%)\end{array}$ & $\begin{array}{c}\text { Misorientation } \\
\text { (deg) }\end{array}$ & $\begin{array}{c}\text { Structure } \\
\text { Shift }(\AA)\end{array}$ & $\begin{array}{l}\text { Stacking } \\
\text { Fault (\%) }\end{array}$ \\
\hline o.oo & 0.30 & 0.50 & o.oo \\
\hline 0.00 & 1.00 & 1.00 & 0.00 \\
\hline 0.50 & 4.60 & 1.50 & 0.00 \\
\hline 0.00 & 8.00 & 2.00 & 0.00 \\
\hline 0.00 & 3.40 & 2.50 & 0.00 \\
\hline 0.00 & 3.00 & 3.00 & 0.00 \\
\hline 0.00 & 8.50 & $3 \cdot 50$ & 0.00 \\
\hline 0.00 & 12.00 & 4.00 & 0.00 \\
\hline 0.00 & $5 \cdot 50$ & $4 \cdot 50$ & 0.00 \\
\hline 0.00 & 4.60 & 5.0 & 0.00 \\
\hline
\end{tabular}

\begin{tabular}{cccc}
$\begin{array}{c}\text { Indentation } \\
(\%)\end{array}$ & $\begin{array}{c}\text { Misorientation } \\
(\mathrm{deg})\end{array}$ & $\begin{array}{c}\text { Structure } \\
\text { Shift }(\AA)\end{array}$ & $\begin{array}{c}\text { Stacking } \\
\text { Fault }(\%)\end{array}$ \\
\hline 4.00 & 0.15 & 0.00 & 10.0 \\
5.00 & 0.30 & 0.00 & 20.0 \\
25.00 & 0.20 & 0.00 & 30.0 \\
25.00 & 0.25 & 0.00 & 40.0 \\
25.00 & 0.30 & 0.00 & 50.0
\end{tabular}

Table S4. Correlation between estimated parameters. Disorder parameters estimated neglecting the very type of stacking disorder/error embedded in the kaolinite numerical model. Highlighted in gray are the actual degrees of disorder for the observed models. As expected, almost perfect agreement was found between estimated and actual disorder degree values if the corresponding type was also included in the multivariate analysis. 

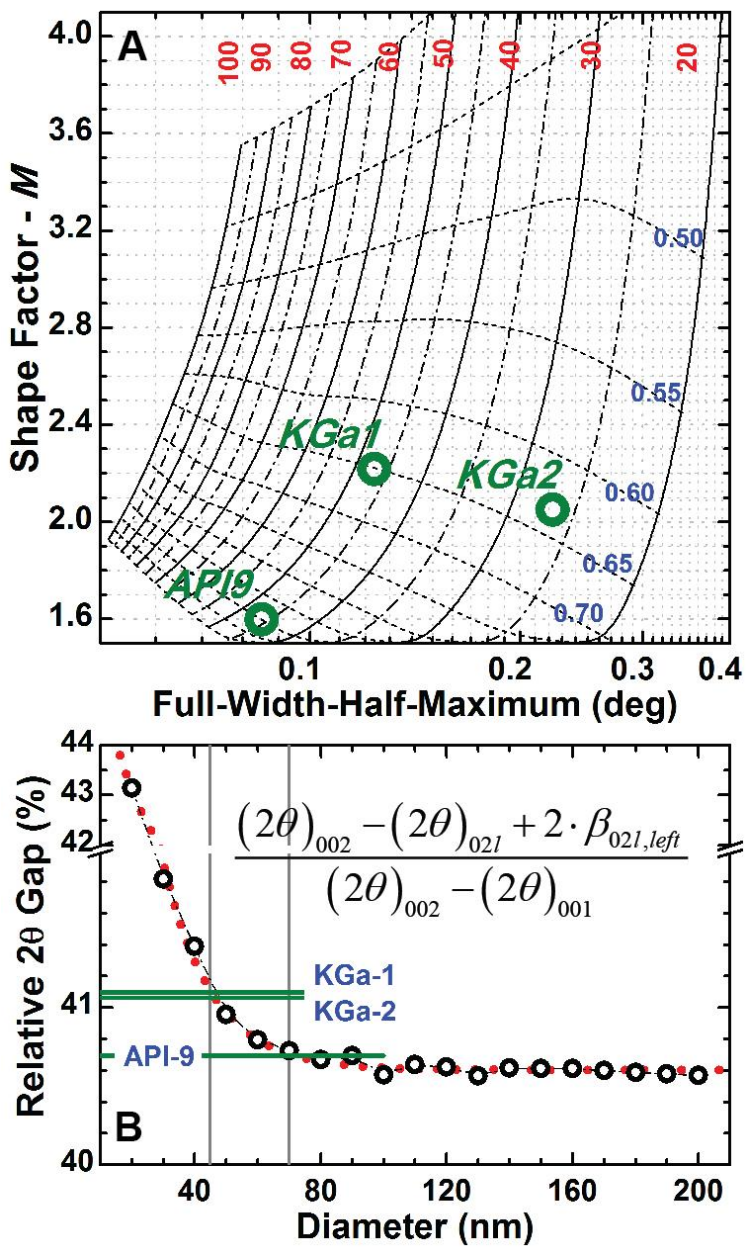

Figure S11. Parametric modification of the PXRD profile as a function of properties for bulk unseparated samples. A, variation of full-width-half-maximum and shape factor (M) of the 002 peak fit with a split Pearson-VII function as a function of the distribution of numbers of layers. B, Relative $02 l-0022 \theta$ gap as a function of the layer diameter. Here o2l refers to the left tail of the $h k l$ band at $\sim 20^{\circ} \mathrm{CuK} \alpha 2 \theta$.

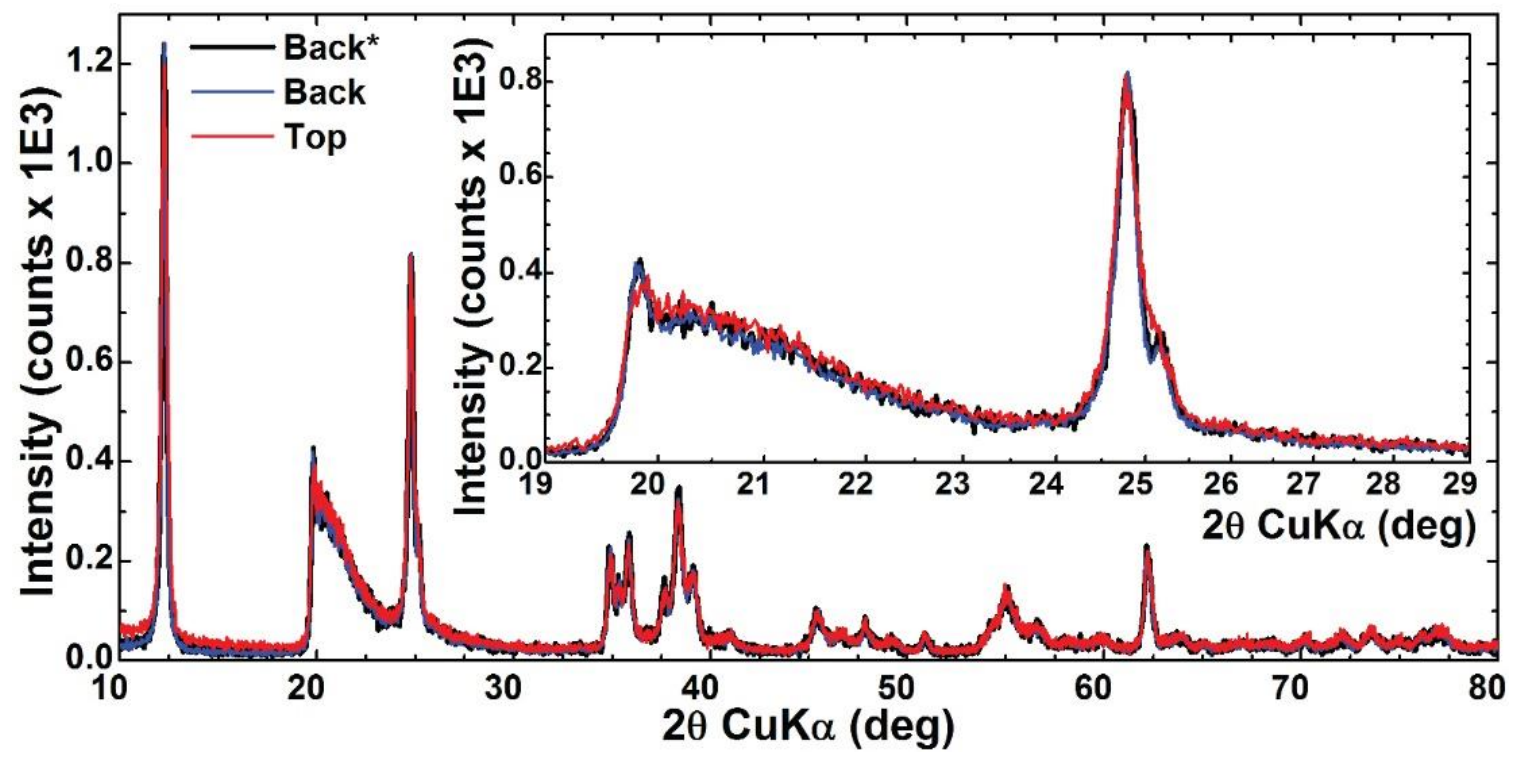

Figure S12. Laboratory powder X-ray diffraction profiles of KGa-2. The profiles were measured adopting different protocols to fill a 1-mm deep cavity flat-plate sample holder. Intensities were rescaled and the diffraction angle shifted (to correct for different specimen displacement) to facilitate comparison of the profiles. 


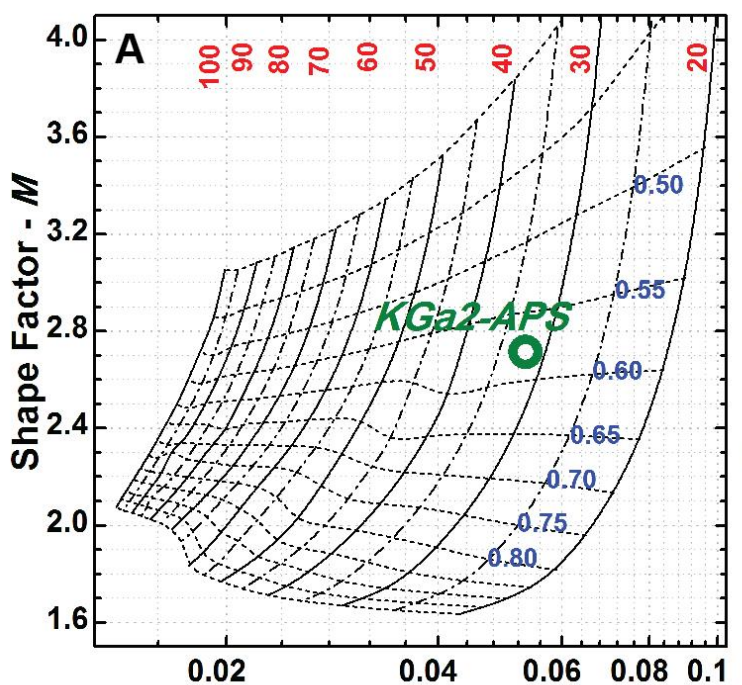

Full-Width-Half-Maximum (deg)

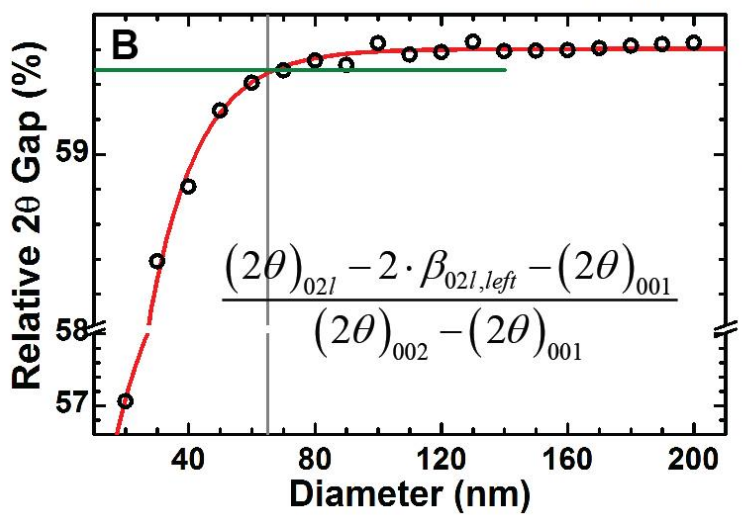

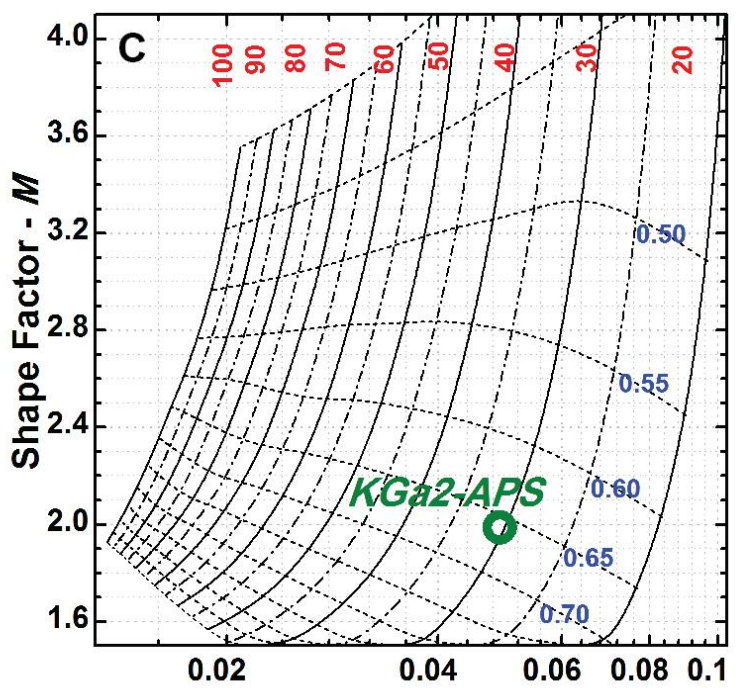

Full-Width-Half-Maximum (deg)

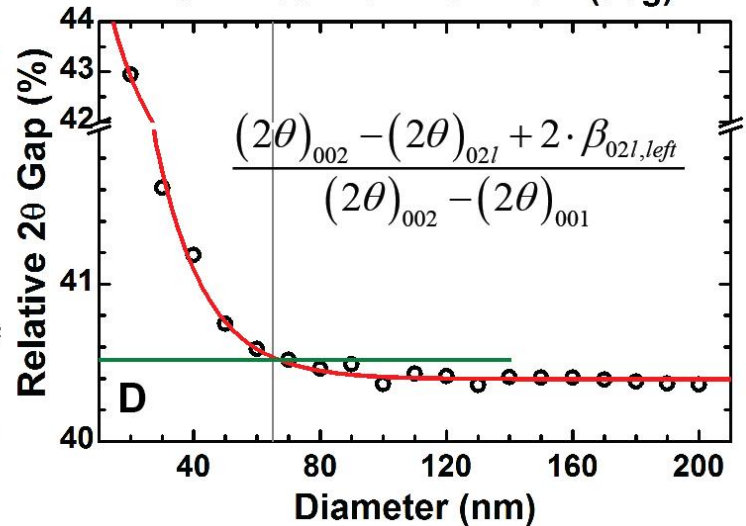

Figure S13. Parametric modification of the PXRD profile as a function of sample properties for data measured with synchrotron radiation. Variation of full-width-half-maximum and shape factor (M) of the oo1 (A) and $002(\mathrm{C})$ peaks fit with a split Pearson-VII function as a function of the distribution of number of layers. Relative o2l-oo1 (B) and o02-02l separation (D) $2 \theta$ gap as a function of the layer diameter. Here $02 l$ refers to the left tail of the $h k l$ band at $\sim 20^{\circ} \mathrm{CuK \alpha} 2 \theta$.

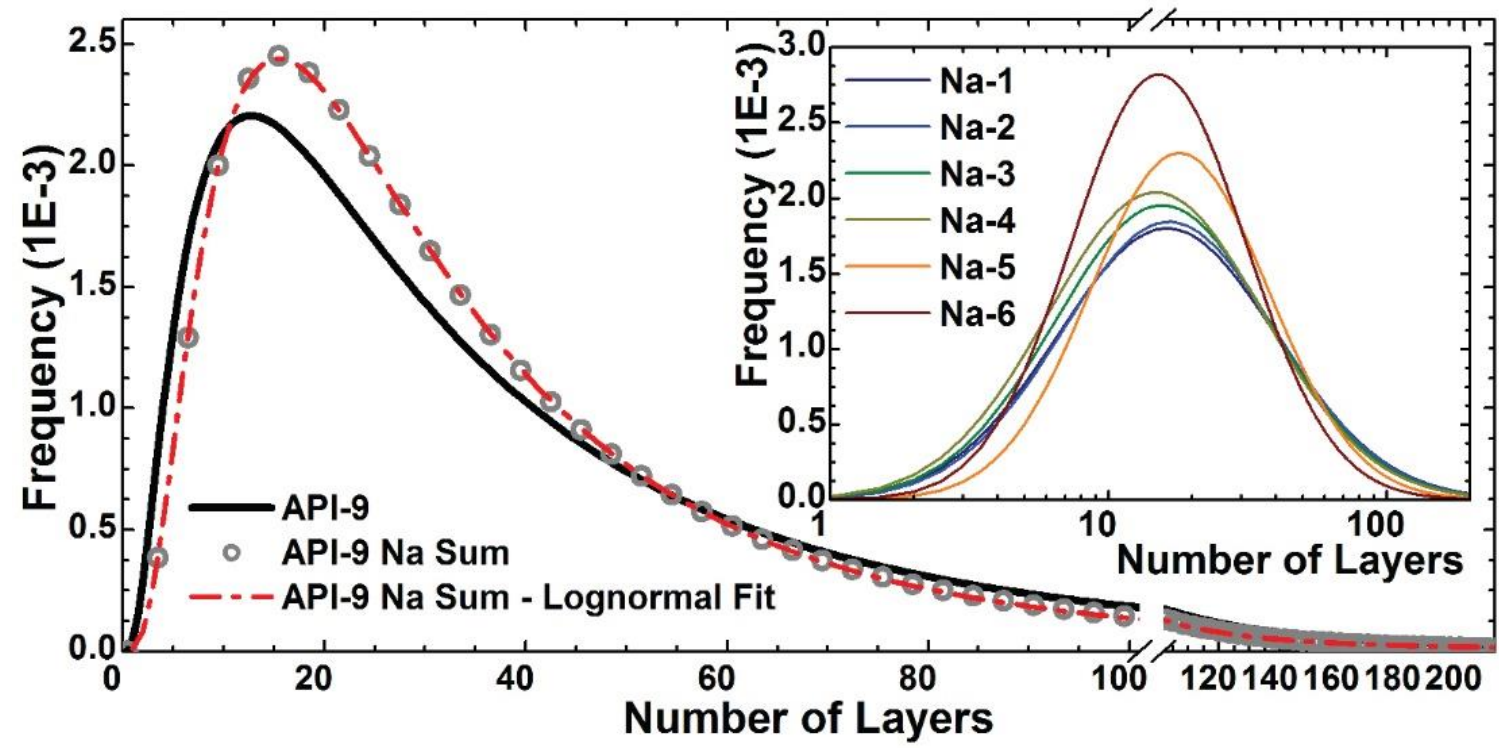

Figure S14. Lognormal distributions of number of layers for the API-9 kaolinite sample. Distribution estimated for the bulk, unseparated sample (black) and as the weighted sum of the distributions from the six particle-size fractions (gray open dots). In the inset are shown the distributions estimated for each of the six particle-size fractions. 


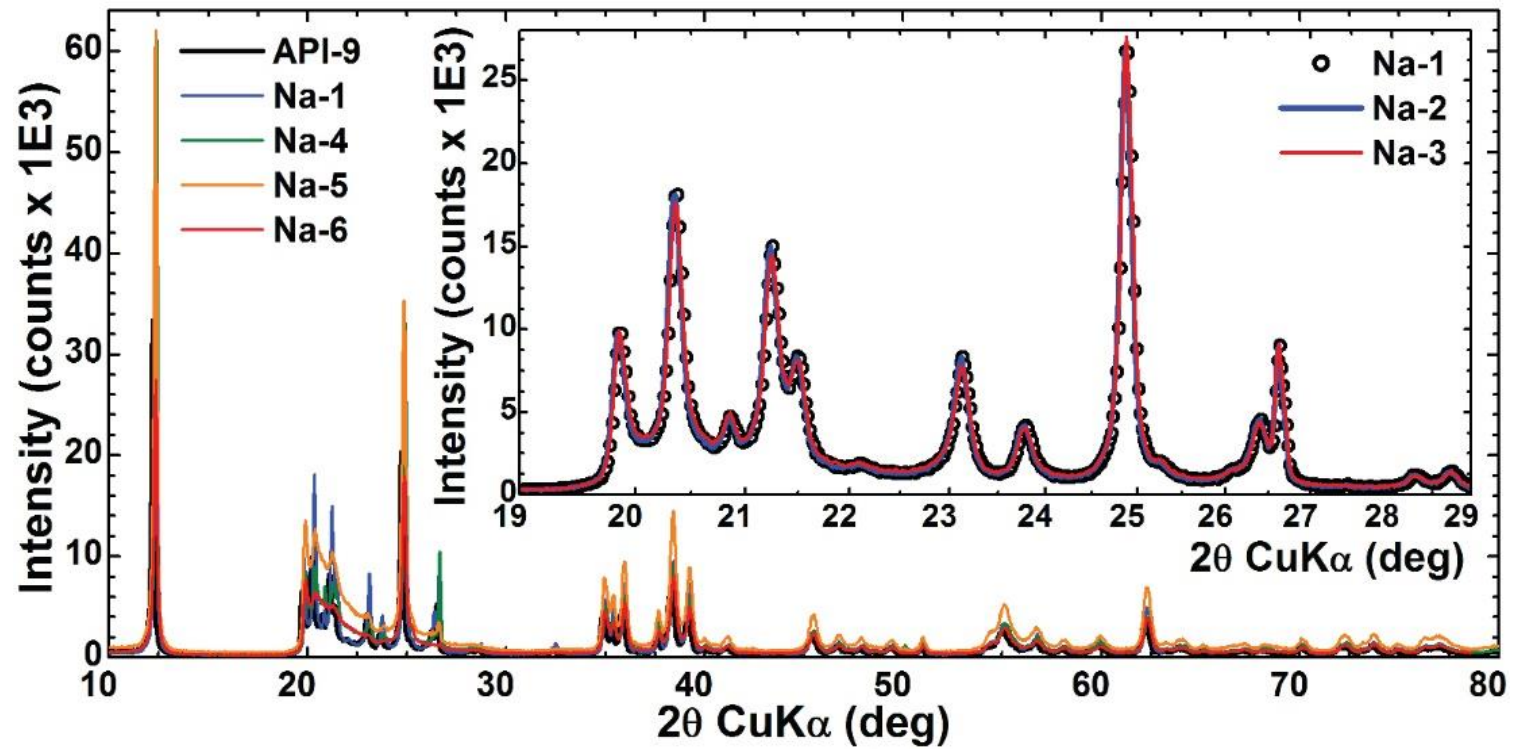

Figure S15. Laboratory powder X-ray diffraction profiles of API-9. The profiles were measured for the standard unseparated sample and for six fractions separated based on particle size. Intensities were rescaled and the diffraction angle shifted (to correct for different specimen displacement) to facilitate comparison of the profiles.

\section{REFERENCES}

(1) Rietveld, H. M. Line Profiles of Neutron PowderDiffraction Peaks for Structure Refinement. Acta Crystallogr. 1967, 22, 151-152.

(2) Rietveld, H. M. A Profile Refinement Method for Nuclear and Magnetic Structures. J. Appl. Crystallogr. 1969, 2, 65-71.

(3) Scardi, P.; Leoni, M. Whole Powder Pattern Modelling. Acta Crystallogr. A 2002, 58, 190-200.

(4) Scardi, P.; Leoni, M.; Dong, Y. H. Whole Diffraction Pattern-Fitting of Polycrystalline Fcc Materials Based on Microstructure. Eur. Phys. J. B 200o, 18, 23-30.

(5) Warren, B. E.; Averbach, B. L. The Effect of Cold-Work Distortion on X-Ray Patterns. J. Appl. Phys. 1950, 21, 595-599.

(6) Warren, B. E.; Averbach, B. L. The Separation of ColdWork Distortion and Particle Size Broadening in X-Ray Patterns. J. Appl. Phys. 1952, 23, 497-497.

(7) Plançon, A.; Zacharie, C. An Expert System for the Structural Characterization of Kaolinite. Clay Min. 1990, 249-26o.

(8) Ufer, K.; Roth, G.; Kleeberg, R.; Stanjek, H.; Dohrmann, R.; Bergmann, J. Description of X-Ray Powder Pattern of Turbostratically Disordered Layer Structures with a Rietveld Compatible Approach. Zeitschrift fur Krist. 2004, 219, 519-527.

(9) Ufer, K.; Kleeberg, R.; Bergmann, J.; Curtius, H.; Dohrmann, R. Refining Real Structure Parameters of Disordered Layer Structures within the Rietveld Method. Zeitschrift für Krist. Suppl. 2008, 2008, 151-158.

(10) Ufer, K.; Kleeberg, R.; Bergmann, J.; Dohrmann, R. Rietveld Refinement of Disordered Illite-Smectite Mixed-Layer Structures by a Recursive Algorithm. II: Powder-Pattern Refinement and Quantitative Phase Analysis. Clays Clay Miner. 2012, 6o, 535-552.

(11) Yang, D.; Frindt, R. F. Powder X-Ray Diffraction of Turbostratically Stacked Layer Systems. Mater. Res. 1996, 11, 17331738.

(12) Bergmann, J.; Friedel, P.; Kleeberg, R. BGMN - a New Fundamental Parameters Based Rietveld Program for Laboratory XRay Sources, It's Use in Quantitative Analysis and Structure Investigations. IUCr Comm. Powder Diffr. Newsl. 1998, 20, 5-8.

(13) Ufer, K.; Kleeberg, R.; Monecke, T. Quantification of Stacking Disordered Si-Al Layer Silicates by the Rietveld Method: Application to Exploration for High-Sulphidation Epithermal Gold
Deposits. Powder Diffr. 2015, 30, S111-S118.

(14) Treacy, M. M. J.; Newsam, J. M.; Deem, M. W. A General Recursion Method for Calculating Diffracted Intensities from Crystals Containing Planar Faults. Proc. R. Soc. A Math. Phys. Eng. Sci. 1991, 433, 499-520.

(15) Leoni, M.; Gualtieri, A. F.; Roveri, N. Simultaneous Refinement of Structure and Microstructure of Layered Materials. J. Appl. Crystallogr. 2004, 37, 166-173.

(16) Jiang, Y.; Cao, L.; Hu, X.; Ren, Z.; Zhang, C.; Wang, C. Simulating Powder X-Ray Diffraction Patterns of Two-Dimensional Materials. Inorg. Chem. 2018, 57, 15123-15132.

(17) Drits, V. A.; Tchoubar, C. X-Ray Diffraction by Disordered Lamellar Structures; Springer: Berlin, 1990.

(18) Sakharov, B. A.; Drits, V. A.; McCarty, D. K.; Walker, G. M. Modeling Powder X-Ray Diffraction Patterns of the Clay Minerals Society Kaolinite Standards: Kga-1, Kga-1b, and Kga-2. Clays Clay Miner. 2016, 64, 314-333.

(19) Drits, V.; Srodoń, J.; Eberl, D. D. XRD Measurement of Mean Crystallite Thickness of Illite and Illite/Smectite: Reappraisal of the Kubler Index and the Scherrer Equation. Clays and Clay Minerals. 1997, pp 461-475.

(20) Bish, D. L.; Dreele, R. B. Von. Rietveld Refinement of NonHydrogen Atomic Positions in Kaolinite. Clays Clay Miner. 1989, 374, 289-296.

(21) Brindley, G. W.; Robinson, K. Randomness in the Structures of Kaolinitic Clay Minerals. Trans. Faraday Soc. 1946, 42, B198.

(22) Murray, H. Structural Variations of Some Kaolinites in Relation to Dehydrated Halloysite. Am. Mineral. 1954, 39, 97-108.

(23) Newnham, R. E. A Refinement of the Dickite Structure and Some Remarks on Polymorphism in Kaolin Minerals. Mineral. Mag. J. Mineral. Soc. 1961, 32, 683-704.

(24) Giese, R. F. Theoretical Studies of the Kaolin Minerals: Electrostatic Calculations. Bull. Mineral. 1982, 105, 417-424.

(25) Plançon, A.; Tchoubar, C. Determination of Structural Defects in Phyllosilicates by X-Ray Powder Diffraction-II. Nature and Proportion of Defects in Natural Kaolinites. Clays Clay Miner. 1977, 25, 436-450.

(26) Bookin, A. S.; Drits, V. A.; Plançon, A.; Tchoubar, C. Stacking Faults in Kaolin-Group Minerals in the Light of Real Structural Features. Clays Clay Miner. 1989, 37, 297-307. 